\title{
Electrochemical Oxidation Treatment of Municipal Solid Waste Landfill Leachate Using Pt Nanoparticles Modified Boron- Doped Diamond Electrode
}

\author{
Yaguang Zhao ${ }^{1}$ Xianying Zhao ${ }^{2, *}$ \\ ${ }^{1}$ School of Environmental and Municipal Engineering, North China University of Water Resources and \\ Electric Power, Zhengzhou 450045, China \\ ${ }^{2}$ Zhengzhou Jize Environmental Protection Technology Co. LTD, Zhengzhou 450007, China \\ *E-mail: rain_8880583@sina.com
}

Received: 25 December 2020 / Accepted: 6 February 2021 / Published: 28 February 2021

\begin{abstract}
This study focused on treatment of municipal solid waste landfill leachate on boron-doped diamond (BDD) and Pt nanoparticles modified BDD (Pt NPs/BDD) by electrochemical oxidation process. The BDD anode was synthesized using MWCVD technique and Pt nanoparticles were electrodeposited on prepared BDD electrodes. The properties of prepared BDD and Pt NPs/BDD anodes were analyzed by SEM, XRD, Raman and electrochemical analyses. The SEM and XRD characterizations showed that the homogeneous and dense diamond crystals covered the both electrode surfaces and for Pt NPs/BDD electrodes, Pt nanoparticles in fcc crystal phase scattered over the BDD surface. Raman analysis indicated to presence of non-diamond carbon impurities in BDD structure and higher degree of lattice imperfections because of the incorporated Pt particles in Pt NPs/BDD structures. The electrochemical oxidation measurements showed that chemical oxygen demand (COD) was decreased about $67.8 \%$, $69.0 \%$ and $71.8 \%$ on BDD, and decreased about $76.4 \%, 84.3 \%$ and $91.9 \%$ on Pt NPs/BDD for current densities of 15,50 and $100 \mathrm{~mA} \mathrm{~cm}{ }^{-2}$, respectively, after 5.5 hours treatment. Results show that $\mathrm{Pt}$ NPs/BDD had the most efficiency to remove COD by electrochemical oxidation process. Scattered Pt nanoparticles on BDD could promote the electrochemical oxidation rate of organic pollutants through the enhancement of the physically adsorbed hydroxyl radicals and chemisorbed oxygen in metal lattice. Thus, there were more oxidation states on the active surface of Pt NPs/BDD electrodes and more adsorbed hydroxyl radicals interacted with BDD surface. Therefore, Pt NPs/BDD in this study provided the synergetic effect of BDD and Pt advantages to electrochemical oxidation of COD.
\end{abstract}

Keywords: Electrochemical oxidation; Treatment; Landfill leachate; Pt nanoparticles, BDD

\section{$\underline{\text { FULL TEXT }}$}

(C) 2021 The Authors. Published by ESG (www.electrochemsci.org). This article is an open access article distributed under the terms and conditions of the Creative Commons Attribution license (http://creativecommons.org/licenses/by/4.0/). 